\title{
GENDER DIFFERENCES IN CREATIVITY AMONG STUDENTS IN PRIVATE HIGHER EDUCATION
}

\author{
Katarina Sokićii, \\ Fayyaz Hussain Qureshi ${ }^{2}$, \\ Sarwar Khawaja ${ }^{3}$ \\ ${ }^{1}$ Dr., Research Associate, \\ Oxford Business College, \\ 65 George Street, Oxford, \\ United Kingdom \\ orcid.org/0000-0001-7522-1228 \\ 2Dr., Director of Research and Quality Assurance, \\ Oxford Business College, \\ 65 George Street, Oxford, \\ United Kingdom \\ ${ }^{3}$ Chairman Business Development, \\ Oxford Business College, \\ 65 George Street, Oxford, \\ United Kingdom
}

\begin{abstract}
:
The primary purpose of this study was to explore the relationship between openness to experience, creativity, creative behaviour, general creativity, and support for creative behaviour from academic staff (lecturers and professors) and by the environment among students in private higher education. The aim was to investigate the contribution of gender, support for creative behaviour from academics, and the environment in predicting different measures of creativity. Additionally, this study examined the structure of the creative behaviour self-assessment questionnaire. The openness to experience scale, creativity subscale, inventory of creative behaviours, creativity selfassessment questionnaire and assessment of incentives for creative behaviour by academics and the environment were tested on a sample of 346 students ( $54 \%$ female), who were randomly selected from different private higher education institutions (college and universities). Students with different majors participated (70\% finance and law, 16\% information technology and $14 \%$ web design). Consistent with our predictions, the 'openness to experience' domain was positively related to the creativity facet, creativity behaviour and general creativity. As expected, the openness to experience domain and its creativity facet and creative behaviour and general creativity were associated with supporting creative behaviour by the environment in both males and females. However,
\end{abstract}

i Correspondence: email katarina.sokić@oxfordbusinesscollege.ac.uk, fayyaz.qureshi@oxfordbusinesscollege.ac.uk, sarwar.khawaja@oxfordbusinesscollege.ac.uk 
contrary to our predictions, support for creative behaviour from academics was unrelated to openness to experience, creativity and general creativity in both males and females. In contrast, support for creative behaviour by academics was related to creative behaviour in females but not in males. Creative behaviour and general creativity were positively associated and supported creative behaviour by academics and the environment. Support for creative behaviour from the environment was positively associated with openness to experience, creativity, creative behaviour and general creativity, while gender only showed independent positive associations with creative behaviour. Gender, support for creative behaviour from academics and support for creative behaviour from the environment together accounted for $9 \%$ of the variance in openness to experience, $7 \%$ of the variance in creativity, $12 \%$ of the variance in creative behaviour and $13 \%$ of the variance in general creativity. The results highlight the importance of support for creative behaviour from the environment in explaining openness to experience, creativity, creative behaviour and general creativity. Furthermore, they show that gender is a significant predictor of creative behaviour. The results also provide further validation of the Inventory of Creative Behaviours and further delineate the nomological network of the creativity construct.

Keywords: creativity, gender differences, students, private higher education

\section{Introduction}

Creativity is a complex, multidimensional construct that encompasses behavioural, biological, cognitive and sociocultural elements, such as genetic, hormonal and neurological and gender differences, as well as personality traits, cognitive strategy and cognitive styles, thinking skills, cultural factors, creative potential and creative achievement (Abraham, 2015). There is no single definition of creativity, but most authors agree that it is the ability to create something new, original and valuable (Baron, 1988; Sternberg, 2005). Nowadays, creativity is the focus of different scientific disciplines, primarily psychology, education, human resource management and medicine. High levels of creativity are a desirable trait in some disciplines (e.g. art, design) as well as a pre-requisite for certain professions. Creativity is a significant predictor of academic achievement (Ai, 1999) and well-being (Acar et al., 2020), which are both related to life success, economic prosperity and social stability. Kaufman \& Beghetto (2009) classify creativity as one of the most important economic resources of today. Creativity includes flexibility, originality and divergent thinking (Barron \& Harrington, 1981).

Amabile (1983) emphasises the theoretical complexity of the creativity construct and states that creativity is influenced by three groups of factors: personality traits, cognitive abilities and the social environment.

Numerous studies and meta-analyses have shown that personality traits (especially openness to experience and introversion) explain a significant amount of the variance in creativity (da Costa et al., 2015; Feist, 1998; von Stumm et al., 2011). However, it should be borne in mind that some aspects of creativity, such as scientific and artistic 
creativity, are related to socially averse personality features, such as low levels of sociability, aggression, dominance and introversion (Stumpf, 1995).

Cognitive abilities include opinion processes (divergent thinking) that lead to creative production. Dominant measures of creativity from this cognitive position are Gilford's tests of divergent thinking (Guilford, 1971) and Torrance's tests of creativity thinking (Torrance, 1974). Divergent thinking is characterised by finding a variety of solutions to a problem (Guilford, 1971) whereby the results depend on the type of tasks performed and the method of evaluation (Wallach \& Kogan, 1965). According to Guiford (1971), divergent thinking is the core of creativity, while other authors (i.e. Runco, 2008; Runco et al., 2006) warn that divergent thinking is a significant predictor of creativity, but it is not synonymous with creativity.

Social and environmental factors, such as cultural diversity, model availability, financial support, external evaluations and supervision, significantly influence eminent creativity (Csikszentmihalyi, 1990; Simonton, 2000). A meta-analysis of 120 studies by Gajda et al. (2016) demonstrated a positive relationship between creativity and academic achievement, which was moderated by the types of measures used to assess these constructs.

In the last two decades, an increasing amount of research has been dedicated to examining gender differences in creativity. However, the results of these studies show that the role of gender in creativity is unclear, especially considering that there have been few neuroscientific investigations. Specifically, most research into this phenomenon is behavioural and has shown that gender differences in creativity are influenced by cognitive styles or adopted strategies that differ in men and women (Abraham, 2015).

\section{Creativity, gender and personality - overview}

Some researchers (e.g., von Stumm et al., 2011) state that personality explains a significant amount of variance in creativity. Sternberg \& Lubart (1995) also propose that personality is related to creativity. It has been shown that creative individuals are reserved, dominant, serious, sensitive, self-sufficient and ignore rules (Guastello, 2009). In his meta-analysis comparing scientists with non-scientists, creative scientists with less creative scientists, and artists with non-artists, Feist (1998) discovered that creative people are generally more open to experience, less conscientious and more introverted. It should also be noted that other studies have found a consistent link between openness to experience and creativity and a somewhat less clear relationship between other traits and creativity. Other authors emphasise the importance of knowledge (Hayes, 1989), talent and temperament (Averill \& Nunley, 1992) in some forms of complex creativity. In addition to investigating artistic and scientific creativity, many authors also researched everyday creativity, i.e., creativity in ordinary people who are not well-known, as well as prominent artists, scientists or inventors. Lin et al. (2012) state that divergent thinking tests are most commonly used to measure creativity in such cases. 
Interestingly, several studies (Lin et al., 2012; McCrae, 1987; von Stumm et al., 2011) have shown that, when examining the association of divergent thinking with broader personality dimensions, a consistent link with openness to experiences is also obtained. Much research in psychology focusses on creativity and the differences that distinguish creative individuals from non-creative individuals. Previous knowledge about creative individuals' personalities were focused on their characteristics, intellectual abilities, knowledge and opinion styles, motivation and status in society.

Lubart (1994) formed a constellation of five personality characteristics important for creativity: tolerance of uncertainty, openness to new experiences, willingness to take risks, the strength of self-confidence, and perseverance. Regarding the observed gender differences in creativity, historical research shows that there have been more creative men throughout history in the fields of art, literature, music, science, and technology.

Modern research explains gender differences in creativity as a consequence of learning stereotypical gender roles (socialisation). With the emancipation of women, gender differences in creativity are decreasing to a greater extent than ever before. Furthermore, a recent meta-analysis by Taylor \& Barbot, 2021 showed that gender differences in creativity are inconsistent across different domains and tasks.

A second-order meta-analysis conducted by da Costa et al. (2015) showed that openness to experience, emotional intelligence, divergent thinking, intrinsic motivation, positive affect and androgyny, are all positively related to creativity. Moreover, their meta-analysis showed that creativity is, to a lesser degree, related to intelligence, extrinsic motivation, self-efficacy and the female gender.

The results of a study by Matud \& Grande (2007), which examined gender differences in creative thinking, showed that women with university-level education scored significantly higher on measures of creative thinking than women with only a primary or secondary level of education and that women with university-level education significantly surpass men in some aspects of creativity, such as verbal fluency.

\section{Current study: objectives and hypotheses}

The primary aim of this study was to investigate the associations between openness to experience, creativity, creative behaviour, general creativity, support for creative behaviour from academics and support for creative behaviour by the environment, as well as the gender differences in these variables among students in private higher education. A further aim of this study was to investigate the contribution of gender and levels of support for creative behaviour from academics and the environment in predicting different measures of creativity. Additionally, this research examined the structure of the self-assessment of creative behaviour. We focused on students at private higher education institutions (college and universities) because this population has certain characteristics that distinguish it from public educational institutions. The number of students in the private higher education sector is growing year on year, and this trend is apparent in most parts of the world (Qureshi \& Khawaja, 2021). 
The demographic characteristics of students in private higher education institutions show some sociodemographic differences compared to those in the public sector. For example, the results of a study by Shury et al. (2016) showed that students in the private sector are on average older $(60 \%$ are under 30$)$ than those in the public sector (80\% are under 30$)$. Furthermore, half of the student population in the private sector are from ethnic minorities, while in the public sector, only a fifth students are from ethnic minorities.

To our knowledge, this research is the first to examine gender differences in creativity among students in the private higher education sector.

The HEXACO model's description of the 'openness to experience' personality domain (which includes the creativity facet used in our study) involves elements such as enjoyment of the arts; the tendency to explore the new, the unknown and the unusual, and the tendency to look for new solutions to problems (Lee \& Ashton, 2004, Ashton \& Lee, 2008). We predicted that openness to experience would be positively correlated with creativity, creative behaviour and general creativity. We are also bearing in mind that support from within the education system (primarily from teachers and academics), family members and society in general significantly influences the development of creativity. Therefore, we expected that the 'openness to experience' domain and creative behaviour and general creativity would be positively related to support for creative behaviour from academics and the environment in both males and females.

Based on previous research, which shows a positive association between creative behaviour and general creativity (e.g. Ljubotina et al., 2015), we expected positive associations between these variables in both males and females. Furthermore, in line with a previous study by Ljubotina et al., (2015) we predicted positive associations between support for creativity from academics and support for creative behaviour from the environment in both genders.

\section{Method}

\subsection{Participants}

A sample of 370 students took part in the study. The students were randomly selected from private higher education institutions (colleges and universities) in Croatia. Students from different disciplines participated in the study $(70 \%$ finance and law, $16 \%$ information technology, and 14\% web design). The data were collected online during the spring of 2021. The questionnaire data of 24 participants were excluded from analysis due to missing data, so the final sample comprised 346 students (Mage $=23.7, S D=5.29$, range $=18-42 ; 54 \%$ female). Participation was on a voluntary basis and students gave their consent to take part in the study. They were asked to complete a battery of selfreporting measures anonymously and received no compensation for their participation. 


\subsection{Measures}

\subsubsection{Openness to experience and creativity}

The openness to experience personality dimension was measured using 16 items from the 100-item Croatian version of HEXACO-PI-R (Ashton \& Lee, 2007; Babarović \& Šverko, 2013). The Openness to Experience dimension contains the following subscales: Aesthetic Appreciation, Inquisitiveness, Creativity and Unconventionality. In addition, items are rated on a 5-point Likert scale ranging from 1 (strongly disagree) to 5 (strongly agree). Scores for this personality dimension were calculated as sums of ratings on associated items divided by several items per scale.

This study measured creativity as personality traits by the Creativity facet of the HEXACO Openness to Experience dimension. The creativity facet consists of 4 items (e.g. "I would enjoy creating a work of art, such as a novel, a song or a painting"; "People have often told me that I have a good imagination").

\subsubsection{Creative behaviour}

Creative behaviour was measured by 29 items specifically created for the purposes of this research and was modelled on similar inventories of self-assessment of creative behaviour, such as the Biographical inventory of Creative Behaviours (BICB; Batey, 2007). The questionnaire describes behaviours that constitute an effort to produce something new and original. Participants were asked how often they had ever engaged in a specific creative activity (e.g., write an essay, design a game, play musical scrap, make jewellery, create a comic book, paint the surface of a glass or wall, create a gift for someone, design a website) on a three-point scale (1 - never, 2 - once or only a few times, 3 - often).

\subsubsection{General creativity}

General creativity was measured by the Creativity Self-assessment Questionnaire (Ljubotina et al., 2015). The questionnaire contains 10 claims (e.g., "I often feel like I'm full of ideas"; ,"I consider myself to be a creative person"; "It's easy for me to come up with more solutions to a problem"). Participants assessed the extent to which each statement applies to them on a four-point scale from 1 (it doesn't apply to me at all) to 4 (it absolutely applies to me). The total score on this scale is calculated as sums of ratings on associated items divided by the number of items per scale.

\subsubsection{Supporting creative behaviour by academics and environment}

In questions about supporting and rewarding creative behaviour, participants assessed the degree of support from academics and the environment on a five-point scale from 1 (none) to 5 (regularly).

\subsection{Data analyses}

In this study, two main analytic approaches were used. Firstly, zero-order correlations (Pearson's r) were used to quantify bivariate relationships between all scales and subscales. To assess the incremental contributions of gender in predicting scores on openness to experience, creativity, creative behaviour and general creativity, four 
hierarchical multiple regressions were performed with the scores for each of the scales and subscales as the criterion variables. The gender variable was entered in Step 2 of the multiple regressions. Given the wide age range of the participants (from 18 to 42), age was included as a control variable in Step 1 of the regression analyses. Significant differences in correlations between openness to experience, creativity, creative behaviour, general creativity, support creative behaviour from academics and environment across gender were tested via Fisher r-to-z transformation.

\section{Results}

\subsection{Factor structure of inventory of creative behaviours}

The appropriateness of the correlation matrix for factorisation was verified with the Kaiser-Meyer-Olkin coefficient, which was .825, and Bartlett's test of sphericity (approx. Chi-square $=1922.87, \mathrm{df}=406, \mathrm{p}<.001$ ), which indicates the adequacy of the correlation matrix analyses. Both Kaiser-Guttman criterion and Scree-test clearly yielded a threefactor solution, which accounted for $61.60 \%$ of the variance of creative behaviour. The three extracted components were rotated to varimax solutions. In this study, we investigated creativity behaviour as a unitary construct and, therefore, different forms of this behaviour are not the focus of our attention.

\subsection{Descriptive statistics}

The descriptive data from all the questionnaires (range, means, standard deviations, Cronbach's alpha, skewness, kurtosis), gender differences in mean scores and internal consistency values are shown in Table 1. All scales and subscales demonstrated an adequate range and internal psychometric characteristics. Cronbach's alpha was from .74 (for creativity) to 86 (for self-assessment creative behaviour). Skewness and kurtosis for all scales were within the recommended values for normal distribution (between -2 to +2 ) (Gravetter \& Wallnau, 2014). A one-way ANOVA was used to compare males and females in the mean level of openness to experience, creativity, self-assessment creative behaviour, self-assessment creativity and support for creative behaviour from academics and the environment. Mean values were higher on most of the scales and subscales in both males and females, indicating that participants perceive themselves as creative people. As shown in Table 1, Cohen's d indicated gender differences in openness to experience in favour of males $(d=0.29)$, which is in line with previous findings (e.g. Lee \& Ashton, 2004).

Table 1: Descriptive data and internal consistency values in male $(n=159)$ and female $(n=187)$

\begin{tabular}{|c|c|c|c|c|c|c|c|c|c|}
\hline & Male & Female & & & & & & & \\
\hline Variable & $M(S D)$ & $M(S D)$ & $F$ & $d$ & Min & Max & $\alpha$ & $S k$ & $K u$ \\
\hline $\begin{array}{l}\text { Openness to } \\
\text { experience }\end{array}$ & $59.50(7.80)$ & $56.91(10.06)$ & .01 & 0.29 & 26 & 79 & .82 & .05 & -.17 \\
\hline Creativity & $14.36(2.82)$ & $14.38(3.74)$ & .33 & 0.01 & 4 & 20 & .74 & -.09 & -.36 \\
\hline $\begin{array}{l}\text { Creative } \\
\text { behaviour }\end{array}$ & $53.37(8.43)$ & $56.08(9.68)$ & $3.42^{*}$ & 0.30 & 37 & 85 & .86 & .32 & -.27 \\
\hline
\end{tabular}




\begin{tabular}{|c|c|c|c|c|c|c|c|c|c|}
\hline General creativity & $28.41(4.91)$ & $29.54(5.24)$ & 1.97 & 0.22 & 16 & 40 & .81 & .01 & -.68 \\
\hline $\begin{array}{l}\text { Support for } \\
\text { creative } \\
\text { behaviour from } \\
\text { academics }\end{array}$ & $3.27(1.06)$ & $3.26(.90)$ & .00 & 0.01 & 1 & 5 & - & .02 & -.26 \\
\hline $\begin{array}{l}\text { Support for } \\
\text { creative } \\
\text { behaviour by the } \\
\text { environment }\end{array}$ & $3.25(1.08)$ & $3.26(.99)$ & .00 & 0.01 & 1 & 5 & - & .04 & -.48 \\
\hline \multicolumn{10}{|c|}{$\begin{array}{l}\text { Note: } M=\text { mean on item level, } S D=\text { standard deviation, } d=\text { Cohen's } d \text { index. According to Cohen's (1988) } \\
\text { interpretation of effect size, effect sizes around } 0.2 \text { are considered small, } 0.5 \text { medium, and } 0.8 \text { large, } S k= \\
\text { skewness, } K u=\text { kurtosis, } \alpha=\text { Cronbach's alpha. } \\
{ }^{*} p<.05,{ }^{* *} p<.01,{ }^{* * *} p<.001 .\end{array}$} \\
\hline
\end{tabular}

It is important to note that significant gender differences in openness to experience $(d=$ 0.62 ) and creativity ( $d=0.53$ ) were found in an earlier study conducted by Babarović \& Šverko (2013) but in favour of females. Small but significant differences in the selfassessment of creative behaviour $(d=0.30)$, and creativity $(d=0.22)$ were found in favour of females. At the same time, there were no gender differences in creativity, support for creative behaviour from academics, and support for creative behaviour from the environment.

The results of Fisher's $r$ to $z$ transformation (Table 2) showed that there were statistically significant differences in correlations across gender between the openness to experience domain and its creativity facet $(r$ male $=.62, r$ female $=.79, z=-3.181, p=0.001)$ and gender-moderated observed relationships between openness to experience and general creativity ( $r$ male $=.43$, rfemale $=.56, z=-1.589, p=0.04$ ). Statistically significant differences in correlations across gender were found between creative behaviour and general creativity ( $r$ male $=.39$, rfemale $=.60, z=-2.585, p=0.005$ ). Therefore, we present below the correlations from our regression analyses according to gender.

Table 2: Results of Fisher's $r$ to $z$ transformation in male $(n=159)$ and female $(n=187)$

\begin{tabular}{|c|c|c|c|c|c|}
\hline & Creativity & $\begin{array}{c}\text { Creative } \\
\text { behaviour }\end{array}$ & $\begin{array}{l}\text { General } \\
\text { creativity }\end{array}$ & $\begin{array}{l}\text { Support for } \\
\text { creative } \\
\text { behaviour } \\
\text { from } \\
\text { academics }\end{array}$ & $\begin{array}{l}\text { Support for } \\
\text { creative behaviour } \\
\text { from the } \\
\text { environment }\end{array}$ \\
\hline $\begin{array}{l}\text { Openness to } \\
\text { experience }\end{array}$ & $-3.183^{* *}$ & -0.794 & $-1.589^{*}$ & 0.744 & 0.397 \\
\hline Creativity & & -.1 .057 & -1.239 & 0.837 & 0.300 \\
\hline $\begin{array}{l}\text { Creative } \\
\text { behaviour }\end{array}$ & & & $-2.585^{* *}$ & -0.283 & -1.025 \\
\hline General creativity & & & & -0.464 & -0.211 \\
\hline $\begin{array}{l}\text { Support for } \\
\text { creative behaviour } \\
\text { from academics }\end{array}$ & & & & & 0.127 \\
\hline
\end{tabular}

Note: ${ }^{*} p<.05,{ }^{* *} p<.01,{ }^{* * *} p<.001$. Fisher's $z$ values are shown. 


\subsection{Correlations analyses}

Bivariate correlations between scales and subscales for both male and female are shown in Table 3. Consistent with our predictions, openness to experience correlated positively with creativity, creative behaviour and with general creativity in both male and female. Correlations between the openness to experience domain and creativity facet were high in both males $(r=.62, p=.000)$ and females $(r=.79, p=.000)$. Strong correlations were also found between openness to experience and creative behaviour in both males $(r=.40, p=$ $.000)$, and females $(r=.47, p=.000)$, as well as between openness to experience and general creativity in males $(r=.43, p=.000)$ and females $(r=.56, p=.000)$

As predicted, the openness to experience domain and its creativity facet and creative behaviour and general creativity were positively related to support for creative behaviour from the environment in both males and females. Furthermore, in line with expectations, creative behaviour was positively related to support for creative behaviour from academics but only in women $(r=.18, p<.05)$. In males, creative behaviour is unrelated to academics' support for creative behaviour $(r=.15, p>.05)$. General creativity shared moderate to significant positive correlations with the majority of the measured variables except with support for creative behaviour from academics in both genders.

Creative behaviour positively correlated to a lesser degree with support for creative behaviour from academics in females $(r=.18, p<0.05)$, while in males, the correlation between self-assessed creative behaviour and support for creative behaviour from academics was insignificant $(r=.15, p=.263)$. Contrary to expectations, openness to experience, creativity and general creativity were unrelated to the support for creative behaviour from academics in both males and females. Thus, Hypothesis 2 was partially supported. In line with our prediction, creative behaviour was positively related to general creativity in males $(r=.39, p<.001)$ and females $(r=.60, p<.001)$. As expected, support for creative behaviour from academics and the environment highly correlated in males $(r=.53, p<.001)$, and females $(r=.52, p<.001)$.

Table 3: Bivariate correlations (Person's r) among the measured variables in male $(n=159)$ and female $(n=187)$

\begin{tabular}{|l|c|c|c|c|c|c|}
\hline & $\mathbf{1}$ & $\mathbf{2}$ & $\mathbf{3}$ & $\mathbf{4}$ & $\mathbf{5}$ & $\mathbf{6}$ \\
\hline 1. Openness to experience & - & $.62^{* * *}$ & $.40^{* * *}$ & $.43^{* * *}$ & .15 & $.29^{* *}$ \\
\hline 2. Creativity & $.79^{* * *}$ & - & $.42^{* * *}$ & $.53^{* * *}$ & .15 & $.30^{* * *}$ \\
\hline 3. Creative behaviour & $.47^{* * *}$ & $.51^{* * *}$ & - & $.39^{* * *}$ & .15 & $.27^{* *}$ \\
\hline 4. General creativity & $.56^{* * *}$ & $.62^{* * *}$ & $.60^{* * *}$ & - & .07 & $.35^{* * *}$ \\
\hline $\begin{array}{l}\text { 5. Support for creative behaviour } \\
\text { from academics }\end{array}$ & .07 & .06 & $.18^{*}$ & .12 & - & $.53^{* * *}$ \\
\hline $\begin{array}{l}\text { 6. Support for creative behaviour } \\
\text { from the environment }\end{array}$ & $.25^{* *}$ & $.27^{* *}$ & $.37^{* * *}$ & $.37^{* * *}$ & $.52^{* * *}$ & - \\
\hline
\end{tabular}

Note: The results for males are above the diagonal and the results for females are below the diagonal. ${ }^{*} \mathrm{p}<.05,{ }^{* *} \mathrm{p}<.01,{ }^{* * *} \mathrm{p}<.001$. 


\subsection{Regression analyses}

Table 4 shows standardised beta coefficients $(\beta)$ from the regression analyses, reflecting the unique contribution of gender, support for creative behaviour from academics and the environment in predicting of openness to experience, creativity, creative behaviour and general creativity.

Table 4: Regression of the creativity on gender $(\mathrm{N}=346)$

\begin{tabular}{|c|c|c|c|c|c|c|c|c|c|c|c|c|}
\hline & \multicolumn{3}{|c|}{$\begin{array}{l}\text { Openness to } \\
\text { experience }\end{array}$} & \multicolumn{3}{|c|}{ Creativity } & \multicolumn{3}{|c|}{$\begin{array}{c}\text { Creative } \\
\text { behaviour }\end{array}$} & \multicolumn{3}{|c|}{$\begin{array}{c}\text { General } \\
\text { creativity }\end{array}$} \\
\hline & $\beta$ & $t$ & $p$ & $\beta$ & $t$ & $p$ & $\beta$ & $t$ & $p$ & $\beta$ & $t$ & $p$ \\
\hline \multicolumn{13}{|l|}{ Step 1} \\
\hline Age & .13 & 1.82 & .07 & .07 & .89 & .38 & .10 & 1.35 & .18 & .00 & .03 & .98 \\
\hline$R$ & .13 & & & .07 & & & .10 & & & .00 & & \\
\hline$R^{2}$ & .03 & & & .00 & & & .01 & & & .00 & & \\
\hline Adj. $R^{2}$ & .01 & & & -.00 & & & .00 & & & -.01 & & \\
\hline \multicolumn{13}{|l|}{ Step 2} \\
\hline Age & $.14^{*}$ & 2.04 & .04 & .08 & 1.12 & .27 & .11 & 1.58 & .12 & .02 & .29 & .77 \\
\hline Gender & -.12 & -1.71 & .09 & .01 & .12 & .90 & $.14^{*}$ & 2.05 & .04 & .11 & 1.65 & .10 \\
\hline $\begin{array}{l}\text { Support } \\
\text { academics }\end{array}$ & -.07 & -.88 & .38 & -.10 & -.1 .15 & .25 & -.02 & -.23 & .82 & -.11 & -1.41 & .16 \\
\hline $\begin{array}{l}\text { Support } \\
\text { environ. }\end{array}$ & .28 & 3.57 & .00 & .33 & 3.94 & .00 & .34 & 4.22 & .00 & .42 & 5.17 & .00 \\
\hline$R$ & .32 & & & .30 & & & .38 & & & .39 & & \\
\hline$R^{2}$ & .10 & & & .09 & & & .14 & & & .15 & & \\
\hline Adj. $R^{2}$ & $.09^{* *}$ & & & $.07^{* *}$ & & & .12 & & & .13 & & \\
\hline
\end{tabular}

Note: Standardized regression coefficients $(\beta) . R$ = coefficient of determination. $R^{2}=$ squared multiple $R$. Adj. $R^{2}=$ Adjusted $R$ Square. Bolded values of $\beta$ indicate effects that are significant at $p<.001$.

${ }^{*} p<.05,{ }^{* *} p<.01$

Within the joint regression analysis, support for creative behaviour from the environment showed independent positive associations with all criterion variables ( $\beta$ for openness to experience $=.28, \beta$ for creativity $=33, \beta$ for creative behaviour $=34$, and $\beta$ for general creativity $=.42$, all $\mathrm{p}<.001)$. On the other hand, gender showed positive associations in terms of beta weights only with creative behaviour $(\beta=.14, p=.04)$.

Gender, support for creative behaviour from academics, and support for creative behaviour from the environment together accounted for $9 \%$ of the variance in openness to experience, $7 \%$ of the variance in creativity, $12 \%$ of the variance in creative behaviour and $13 \%$ of the variance in general creativity (Table 4 ).

\section{Discussion}

The major aim of this study was to investigate the associations between openness to experience, creativity, creative behaviour, general creativity, support for creative behaviour from academics and support for creative behaviour by the environment, as well as gender differences in these variables among students in private higher education. Furthermore, we investigated the contribution of gender, support for creative behaviour 
from academics and the environment in predicting different measures of creativity. Finally, we checked the psychometric characteristics of the Inventory of Creative Behaviours constructed for the purposes of this research.

According to our knowledge and the available literature, creativity among students in private higher education institutions had not been examined previously. In addition, no research had previously been performed on gender differences in levels of creativity of students at private higher education institutions. However, in the last two decades, the number of studies on students at private higher education institutions has grown. In these studies, however, psychological constructs, such as students' motives, satisfaction, expectations and perceptions are commonly examined (e.g. Barnes, 2007; Min et al., 2012).

Therefore, this research serves as an incentive to conduct further studies involving different psychological constructs on separate populations of students in order to determine the existence of differences between them. Generally, the results of the study confirmed most of our hypotheses and demonstrated the reliability and accurate psychometric characteristics of our measurements of creative behaviour.

Overall, gender, support for creative behaviour from academics and support for creative behaviour from the environment explained $9 \%$ of the variance in openness to experience, $7 \%$ of the variance in creativity, $12 \%$ of the variance in creative behaviour and $13 \%$ of the variance in general creativity.

As expected, in both genders, openness to experience correlated positively with creativity, creative behaviour and general creativity, which is consistent with the theoretical assumptions that openness to experience reflects the need for the new, the unknown and the unconventional and includes intellectual curiosity, imagination, originality, creativity and rebelliousness (Lee \& Ashton, 2004). Furthermore, these results are consistent with previous studies demonstrating that openness to experience consistently predicts creativity (e.g., Silvia et al., 2011; Silvia et al., 2007; Oleynick et al., 2017).

Consistent with our predictions, openness to experience, creativity, as well as creative behaviour and general creativity, were positively related to support for creative behaviour from the environment in both genders, which is in line with previous findings (Ljubotina et al., 2015).

The regression analyses also showed that environmental support is a strong positive predictor of openness to experience, creativity, creative behaviour, and general creativity, while gender only significantly predicts creative behaviour. These results are similar to Ljubotina et al's. (2015) findings, which also confirmed that environment support positively predicts different forms of creative behaviour (e.g. making original objects, art and technical creations, creations in the field of music and games) and general creativity to a significant extent. These findings emphasise the importance of environmental support in developing and expressing creativity and show that creativity is a construct that significantly depends on environmental factors. Therefore, it will be crucial for future research to examine which environmental factors in particular affect an 
individual's creativity (e.g. family, friends, the wider social environment, material opportunities, leisure activities, availability of information, leisure time, etc.).

Contrary to expectations, there was no significant association between support for creative behaviour offered academics and students' openness to experience, creativity, creative behaviour and general creativity, which may be related to the age of the student population (adults), who have developed their creative potential. Another reason may be the fact that the research was conducted during the COVID-19 pandemic, so a large proportion of first-year students had less contact with academics. Only in females, creative behaviour positively correlated to a lesser degree with support for creative behaviour from academics $(\mathrm{r}=.18, \mathrm{p}<.05)$, indicating that there are gender differences in the perception of support and that creativity in females is more influenced by environmental factors, including support from academics. After all, the association between creative behaviour and environmental support is greater in women $(\mathrm{r}=.37, \mathrm{p}<$ $.001)$ than in men $(r=.27, p<.01)$, although the difference in these correlations is not statistically significant.

With respect to the relationship between gender and creativity, females in the current study scored significantly higher than females on the self-assessed measurement of creative behaviour, replicating findings from previous studies of students and adults from the community (e.g., Lee \& Ashton, 2004). However, other studies show that males achieve higher results on different measures of creativity and creative behaviour (e.g., Abraham, 2015; Babarović \& Šverko, 2013; Chan, 2005; He \& Wong, 2021; Kaufman, 2006). In summary, the results from the current work provide further evidence that the different measures of creativity are distinct yet partially overlapping components of a coherent construct of creativity.

In general, relationships between creativity and creative behaviour and creativity scores observed in the current study were consistent with ideas about personality traits associated with creativity and are in line with previously published findings regarding associations between the two (von Stumm et al., 2011).

\subsection{Limitation and future direction}

Our findings must be considered in the light of certain limitations. Firstly, a notable limitation concerns our exclusive reliance on self-reporting measures, which may have inflated observed associations between openness to creativity domains, creativity facet, and creative behaviour, as well as general creativity scores. Secondly, participants were recruited online, and the study sample consisted of the student population. Thirdly, students were randomly selected with different majors (70\% finance and law, 16\% information technology and $14 \%$ web design) from private higher education institutions (colleges and universities) and differ in terms of their individual preferences, motivation, and areas of study.

Therefore, future research on creativity should be conducted on a homogeneous student population from different fields, such as architecture, painting, mathematics, choreography, acting, and compare them with levels of creativity in students from other 
fields of study. In addition, future studies should compare the creativity of students in the public and private sectors.

Although our findings provide preliminary support for further research on creativity in the private education sector, they cannot be generalised to other populations. The present study used short, self-assessed measures of creativity, which could have been affected by the participants' desire to present themselves in a favourable light. Therefore, future research should use other measures of creativity, such as divergent thinking tests and creative achievement questionnaires, and compare them with other external outcomes, such as academic achievement.

\section{Conflict of Interest Statement}

The authors declare no conflicts of interests.

\section{About the Authors}

Dr. Katarina Sokić, PhD in Psychology, MSc in Civil Law, Research Associate, Oxford Business College, 65 George Street, Oxford, United Kingdom.

Dr. Fayyaz Hussain Qureshi, BA, (Economics and Journalism), BSc (Botany, Zoology and Chemistry), MA (English Literature), MBA (Marketing), MBA (Finance), MSc (Internet Technologies), Doctorate in Marketing, PGD (Organisations Knowledge), Director of Research and Quality Assurance, Oxford Business College, 65 George Street, Oxford, United Kingdom.

Sarwar Khawaja, MBA, LLM; Chairman Business Development, Oxford Business College, 65 George Street, Oxford, United Kingdom.

\section{References}

Abraham, A. (2015). Gender and creativity: an overview of psychological and neuroscientific literature. Brain Imaging and Behavior, 10(2), 609-618. doi:10.1007/s11682-015-9410-8

Acar, S., Tadik, H., Myers, D., van den Sman, C, Uysal, R. (2020). Creativity and wellbeing: A Meta analysis. The Journal of Creative Behavior, 55(3), 738-751. doi:10.1002/jocb.485

Ai, X. (1999). Creativity and Academic Achievement: An Investigation of Gender Differences. Creativity Research Journal, 12:4, 329-337, doi:10.1207/s15326934crj1204_11

Amabile, T. M. (1983). The social psychology of creativity. New York: Springer - Verlag. Ashton, M. C., \& Lee, K. (2008). Empirical, theoretical, and practical advantages of the HEXACO model of personality structure. Personality and Social Psychology Review,11, 150-166. doi:10.1177/1088868306294907

Averill, J. R., \& Nunley, E. P. (1992). Voyages of the heart: Living an emotionally creative life. New York: The Free Press 
Babarović, T., \& Šverko, I. (2013). The HEXACO personality domains in the Croatian sample. Društvena istraživanja, 3, 397-411. doi:10.5559/di.22.3.01

Barnes, B. R. (2007). Analyzing Service Quality: The Case of Post-graduate Chinese Students. Total Quality Management, 18(3), 313-331. doi:10.1080\%2F14783360601152558

Barron, F. (1988). Putting creativity to work. U: R.J. Sternberg (Ur.), The nature of creativity: Contemporary psychological perspectives (str. 76-98). New York: Cambridge University Press.

Barron, F., \& Harrington, D. M. (1981). Creativity, Intelligence, and Personality. Annual Review of Psychology, 32, 439-476.

Batey, M. (2007). A psychometric investigation of everyday creativity. (Unpublished doctoral theses). University College, London.

Csikszentmihalyi, M. (1990). The domain of creativity. (U M.A. Runco i R.S. Albert (Ur.) Theories of creativity (190-212). Newbury Park, CA: Sage

Chan, D. W. (2005). Self-perceived creativity, family hardiness, and emotional intelligence of Chinese gifted students in Hong Kong. Journal of Secondary Gifted Education, 16, 47-56. doi:10.4219/jsge-2005-471

da Costa, S. Páez, D., Sánchez, F., Garaigordobil, M., Gondim, S. (2015). Personal factors of creativity: A second order meta-analysis. Journal of Work and Organizational Psychology, 31(3), 165-173. doi:10.1016/j.rpto.2015.06.002

Feist, G. J. (1998). A meta-analysis of personality in scientific and artistic creativity. Personality and Social Psychology Review, 2(4), 290-309.

Gajda, A., Karwowski, M., \& Beghetto, R. A. (2016). Creativity and Academic Achievement: A Meta-Analysis. Journal of Educational Psychology, 109 (2), 269-299. doi:10.1037/edu0000133

Gravetter, F. i Wallnau, L. (2014). Essentials of statistics for the behavioral sciences (8th edition). Belmont, CA: Wadsworth.

Guastello, S. J. (2009). Creativity and personality. U: T. Rickards, M. A. Runco i S. Moger (Ur.), Routledge companion to creativity (str. 256-266). Abington, England: Routledge.

Guilford, J. P. (1971). The nature of human intelligence. Ljubljana: Mladinska knjiga

Hayes. J. R. (1989). Cognitive processes in creativity. U: J. A. Glover, R. R. Ronning i C. R. Reynolds (Ur.), Handbook of creativity (str. 135-145). New York: Plenum Press.

He, W.- J., \& Wong W.C. (2021). Gender Differences in the Distribution of Creativity Scores: Domain-Specific Patterns in Divergent Thinking and Creative Problem Solving. Frontiers in Psychology, 12:626911. doi: 10.3389/fpsyg.2021.626911

Kaufman, J. C., \& Beghetto, R. A. (2009). Beyond big and little: The Four C Model of Creativity. Review of General Psychology, 13(1), 1-12. doi:10.1037/a0013688

Kaufman, J. C. (2006). Self-reported differences in creativity by ethnicity and gender. Applied Cognitive Psychology, 20(8), 1065-1082. doi:10.1002/acp.1255.

Lee, K., \& Ashton, M. C. (2004). Psychometric properties of the HEXACO Personality Inventory. Multivariate Behavioral Research, 39, 329-358. doi:10.1207/s15327906mbr3902 8 
Lin, W.-L., Chen, H.-C., Hsu, K.-Y. i Wang, J.-W. (2012). The relations of gender and personality traits on different creativities: A Dual-process theory account. Psychology of Aesthetics, Creativity and the Arts, 6(2),112-123. doi:10.1037/a0026241

Lubart, T. I. (1994). Creativity. U R. J. Sternberg, Thinking and Problem Solving (289-332). New York: Academic Press.

Ljubotina, D., Juničić, N., \& Vlahović-Štetić, V. (2015). Samoprocjene kreativnosti kod srednjoškolaca. Psihologijske teme, 24 (3), 369-399.

Matud, M. P., Rodríguez, C., \& Grande, J. (2007). Gender differences in creative thinking. Personality and Individual Differences, 43(5), 11371147. doi:10.1016/j.paid.2007.03.006

McCrae, R. R. (1987). Creativity, divergent thinking and openness to experience. Journal of Personality and Social Psychology, 52(6), 1258-1265. doi:10.1037/00223514.52.6.1258

Min, S., Khoon, C. C, Tan, B. L. (2012). Motives, Expectations, Perceptions and Satisfaction of International Students Pursuing Private Higher Education in Singapore. International Journal of Marketing Studies, 4(6). doi:10.5539/ijms.v4n6p122

Qureshi, F. H. \& Khawaja, S. (2021). The Growth of Private Higher Education: An Overview in the Context of Liberalisation, Privatisation and Marketisation. European Journal of Education Studies, 8 (9).

Runco, M. A. (2008). Commentary: Divergent thinking is not synonymous with creativity. Psychology of Aesthetics, Creativity, and the Arts, 2(2), 93-96. doi: 10.1037/19313896.2.2.93

Runco, M. A., Dow, G., \& Smith, W. R. (2006). Information, experience, divergent thinking: An empirical test. Creativity Research Journal, 18, 269-277.

Oleynick, V. C., DeYoung, C. G., Hyde, E., Kaufman, S. B., Beaty, R. E., \& Silvia, P. J. (2017). Openness/intellect: The core of the creative personality. In G. J. Feist, R. Reiter-Palmon, \& J. C. Kaufman (Eds.), The Cambridge Handbook of Creativity and Personality Research (pp. 9-27). Cambridge University Press. doi:10.1017/9781316228036.002

Silvia, P. J., Kaufman, J. C., Reiter-Palmon, R., \& Wigert, B. (2011). Cantankerous creativity: Honesty-Humility, Agreeableness, and the HEXACO structure of creative achievement. Personality and Individual Differences, 51(5), 687-689. doi:10.1016/j.paid.2011.06.011

Silvia, P. J., Kaufman, J. C., \& Pretz, J. E. (2009). Is creativity domain-specific? Latent class models of creative accomplishments and creative self-descriptions. Psychology of Aesthetics, Creativity, and the Arts, 3, 139-148.

Simonton, D. K. (2000) Creativity: cognitive, personal, developmental, and social aspects. American Psychology, 55, 151-158. doi:10.1037/0003-066X.55.1.151

Shury, J., Adams, L., Barnes, M., Huntley Hewitt, J., \& Oozeerally, T. (2016). Understanding the Market of Alternative Higher Education Providers and their Students in 2014. London: BIS. Retrieved from 
https://www.gov.uk/government/publications/alternative-providers-ofhighereducation-the-market-and-students-in-2014

Sternberg, R. J. (2005). Kognitiona psihologija. Jastrebarsko: Naklada Slap.

Sternberg, R., \& Lubart, T. (1995). Defying the Crowd; Cultivating Creativity in a Culture of Conformity. New York: Free Press.

Stumpf, H. (1995). Scientific creativity: A short overview. Educational Psychology Review, 7, 225-241. doi:10.1007/BF02213372

Taylor, C. L., \& Barbot, B. (2021). Gender differences in creativity: Examining the greater male variability hypothesis in different domains and tasks. Personality and Individual Differences, 174, 110661. doi:10.1016/j.paid.2021.110661

Torrance, P. E. (1974). The Torrance tests of creative thinking: Technical-norms manual. Bensenville: Scholastic Testing Services

von Stumm, S., Chung, A., \& Furnham, A. (2011). Creative ability, creative ideation and latent classes of creative achievement: What is the role of personality? Psychology of Aesthetics, Creativity and the Arts, 5(2), 107-114. doi: 10.1037/a0020499

Wallach, M. A., \& Kogan, N. (1965). Modes of thinking in young children: A study of the creativity-intelligence distinction. New York: Holt, Rinehart and Winston. 
Katarina Sokić, Fayyaz Hussain Qureshi, Sarwar Khawaja

GENDER DIFFERENCES IN CREATIVITY AMONG STUDENTS IN PRIVATE HIGHER EDUCATION

Creative Commons licensing terms

Author(s) will retain the copyright of their published articles agreeing that a Creative Commons Attribution 4.0 International License (CC BY 4.0) terms will be applied to their work. Under the terms of this license, no permission is required from the author(s) or publisher for members of the community to copy, distribute, transmit or adapt the article content, providing a proper, prominent and unambiguous attribution to the authors in a manner that makes clear that the materials are being reused under permission of a Creative Commons License. Views, opinions and conclusions expressed in this research article are views, opinions and conclusions of the author(s). Open Access Publishing Group and European Journal of Education Studies shall not be responsible or answerable for any loss, damage or liability caused in relation to/arising out of conflicts of interest, copyright violations and inappropriate or inaccurate use of any kind content related or integrated into the research work. All the published works are meeting the Open Access Publishing requirements and can be freely accessed, shared, modified, distributed and used in educational, commercial and non-commercial purposes under a Creative Commons Attribution 4.0 International License (CC BY 4.0). 